6

\title{
Developing Career as a Hospital Cancer Pharmacist in China
}

\author{
Jincheng Yang', ${ }^{1,2}$ Wendi Ge ${ }^{1}$, Wenjing Yang ${ }^{2 *}$ \\ ${ }^{1}$ Department of Pharmacy, National Cancer Center/ National Clinical Research Center for Cancer/ Cancer Hospital, \\ Chinese Academy of Medical Sciences and Peking Union Medical College, Beijing, China \\ ${ }^{2}$ Office for Cancer Diagnosis and Treatment Quality Control, National Cancer Center/ National Clinical Research Center for \\ Cancer/ Cancer Hospital, Chinese Academy of Medical Sciences and Peking Union Medical College, Beijing, China
}

Farmacja Polska, ISSN 0014-8261 (print); ISSN 2544-8552 (on-line)

\begin{abstract}
Adres do korespondencji
Office for Cancer Diagnosis and Treatment Quality Control, National Cancer Center/ National Clinical Research Center for Cancer/ Cancer Hospital, Chinese Academy of Medical Sciences and Peking Union Medical College, Peking, China; e-mail: wenjing86824@126.com
\end{abstract}

\section{Źródła finansowania}

Nie wskazano źródel finansowania.

\section{Konflikt interesów:}

Nie istnieje konflikt interesów.

Otrzymano: 2021.02 .16

Zaakceptowano: 2021.03.18

Opublikowano on-line: 2021.03.26

\section{DOI}

10.32383/farmpol/134636

ORCID

Jincheng Yang (ORCID iD: 0000-0001-8453-8614)

Wendi Ge (ORCID iD: 0000-0001-6833-1760)

Wenjing Yang (ORCID iD: 0000-0002-5505-9793)

\section{Copyright}

(c) Polskie Towarzystwo Farmaceutyczne

To jest artykuł o otwartym dostępie, na licencji CC BY NC (c) (1) (\$)

https://creativecommons.org/licenses/by-nc/4.0/

\section{Developing Career as a Hospital Cancer Pharmacist in China}

Pharmacy in a hospital is a comprehensive and multiple medical service. From the cancer hospital services, pharmacy in hospital sub-specialties include: clinical pharmacy, drug information service, hospital pharmacy dispensing, pharmacy administration, GCP (Good Clinical Practice), hospital preparation, pharmaceutical research, etc. As characters of anti-cancer drugs, cancer pharmacists should focus more on the latest treatment, individualized therapies, biomarkers, drug combinations, drug interactions and sequences. Development for hospital cancer pharmacists include: academic opportunities through scientific research, continuing professional opportunities through standardization training or board certification, and working abroad. It requires the ability of pharmacists to discover and solve potential and practical clinical medication problems, to find new standpoints from directly-facing patients for clinical pharmacy and hospital pharmacy.

Keywords: hospital, cancer, pharmacist, career, development.

(c) Farm Pol, 2021, 77(2): 79-83 
$\mathrm{P}$ harmacy in a hospital is a comprehensive and multiple medical service, including drug supply, pharmaceutical technology, clinical medication, and pharmacy policies and regulations, besides applying kinds of related knowledge into clinical practices. As a patient-centered practice, pharmaceutical care provides direct and drug-related services to improve the safety, effectiveness, and economy in drug treatment, to promote quality of life for both patients and the public.

In a hospital, pharmacists act as a learned intermediary between patients and health care providers advising on rational drug usage, and pharmaceutical care becomes one of the most important roles that pharmacists are currently taking on, involving four main serving objects:

1. patients (e.g., medication consultation, pharmaceutical care, medication guidance, prescription dispensing, treatment scheme designation and adjustment),

2. doctors (e.g., pre-checking prescriptions, prescription audit, ADR (adverse drug reactions) disposal, pharmaceutical consultation, MDT (multidiscipline treatment) team, prescription compilation, drug information),

3. nurses (e.g., drug compatibility, storage time, skin test, infusion speed, instrument requirements, ADR) and

4. the public (e.g., medication science propaganda, free medical consultations [1].

\section{Sub-specialties}

Though there are some differences in some regions or areas or hospitals, pharmacy in hospital sub-specialties mainly include clinical pharmacy, drug information service, hospital pharmacy dispensing, pharmacy administration, GCP (Good Clinical Practice), hospital preparation, pharmaceutical research, etc.

Clinical Pharmacists: as the spearhead, they integrate clinical drug usage with other medication courses:

1. They evaluate and manage the effectiveness of drug treatment within the basis of the institution and patient population, obtain patient medication record for "downstream" caregivers and health care professionals, also provide professional information for medical workers, standardize medication guidelines of overall medical service qualities.

2. They plan and deliver academic detailing programs for the development of hospital pharmacy discipline, participate in various fee-for-service projects (e.g., formulary support, database development, training programs) for clients [2].

3. Their work includes: clinical ward round and consultation, case discussion, suggesting nurses and patients on rational drug treatment, assisting clinicians on clinical observation for new drugs, TDM (treatment drug monitoring), and drug assessment.

Anti-cancer drugs, with the characters of high prices, narrow therapeutic window, serious ADRs and fast-updated guidelines, promote the many key points in quality control. It brings big challenges in clinical rational usage since complex tumor mechanisms, individualized and precise therapies [3]. Cancer pharmacists focus more on the latest treatment, individualized therapies, biomarkers, drug combinations, drug interactions, and sequences.

Information Pharmacists: based on information skills, they handle, process, develop pharmacy information service to ensure patient safety, nurse-care effectiveness, and medical efficiency. Information pharmacists must be able to

1. anticipate and evaluate the DI (drug information) needs of patients and health care professionals;

2. obtain appropriate and complete background information as described under the section Systematic Approach for Responding to Drug Information Requests;

3. use a systematic approach to address DI needs by effectively searching, retrieving, and critically evaluating the literature (i.e., assessment of study design, statistics, bias, limitations, applicability);

4. appropriately synthesize, communicate, document, and apply pertinent information to the patient care situation [2].

Purchasing Pharmacists: they provide comprehensively-ranged drug supply efficiently and timely. This position requires familiarity with the purchasing process, drug rotary system, drug checking, temporary purchasing procedure, etc. Additionally, they focus on: drug loading, price maintenance, expiration date alarm, barcode, medication information consultation, etc.

Dispensing Pharmacists: this position is classified as outpatient dispensing, inpatient dispensing, satellite pharmacy dispensing, special dispensing (e.g., toxic, anesthesia, mental drugs), and warehouse dispensing. Dispensing drug management includes shortages, automated dispensing, packaging and labeling, cold- chain transportation, and technology of electronic communication and electronic medical records, etc. 
Anesthetic Pharmacists: as a branch of dispensing pharmacist and as the particularity of anesthesia in surgical operations, the main tasks for anesthetic pharmacists are base drug management in the form of the total number of unused and used (empty) vials. Besides maintaining automated dispensing machines at satellite pharmacies, anesthetic pharmacists also check doctors' prescriptions every workday.

Quality-control Pharmacists: they conduct checking pharmacy work quality in every sub-group, such as drug signs (e.g., LASA (look-alike and sound-alike) signs, high-alert signs), expiring date, overflowed drugs, drug quality (e.g., storage, preparation, infusion), drug usage (nurse and patient usage), drug assessment (e.g., consistency, drug collection, generic drugs, biological analogs), etc.

GCP Pharmacists: at drug's clinical trial stages, GCP pharmacists check drug status (e.g., receiving, storage, dispensing, recycling), and set a record for each project including drug treatment in GCP wards, meanwhile they accept supervisions and superior inspections. As the core of the whole trial stages, drug management and usage directly influence subject safety and trial results.

Hospital preparation Pharmacists: hospital preparations are those needed drugs that could not be obtained from the market, and its application scope is restricted within the own clinics. Hospital preparation plays an indispensable role in rescuing the wounded, protecting patient health, meeting scientific research needs, and making up for the drug-marketing shortage.

Research Pharmacists: Research qualities and professional level in pharmacy research could reflect disciplinary academic values and scientific capabilities. Its fields involve approved/ investigational drugs, drug-related management, and construction and management of pharmacy laboratory[4]. Clinical research generally falls into:

1. drug storage, preparation, and record keeping, frequently through an investigational drug service, and

2. serving as a principal investigator or a sub-investigator, manager, or coordinator within a research team [5].

\section{Opportunities}

\section{Academic opportunities}

Personal degrees and professional levels can be enhanced through scientific research. Increasing new researches, such as translational medicine, benefit to pharmacists; because hospital researchers could catch clinical medicine trend and urgent problems timely; on the contrary, clinical feedbacks are conducive to improve researches. The featured jobs include inpatient pharmacist, pharmacist lead, clinical pharmacist, pharmacy technician, clinical pharmacy coordinator, clinical pharmacist business analyst, etc. [6].

\section{Continuing professional development}

Professional capability improvement is mainly through standardization training, skill training, further education, seminars, certifications; for example, board certification through the BPS (Board of Pharmacy Specialties) is recognized as the gold standard for determining which pharmacists are qualified to contribute at advanced practice levels [7].

As international conventions, two professional training stages for pharmacy students and residents after graduation are necessary:

1. general pharmacist training stage and

2. special pharmacist training stage. The first stage is general skill training, including prescription checking, dispensing, drug information, adverse drug reaction reports, quality management, and basic pharmaceutic services within three years. According to the degree of faultily, the position rotation frequency varies from 1-3 months[8]. The second stage is special skill education, including professions in clinical pharmacy or specific skill at dispensing within two years[9]. Since the new healthcare reform began in China, other modes for pharmacist training are under research, such as stratified training $[10,11]$.

For example, the community pharmacy residency program is a post-graduate advanced training opportunity where staff will work alongside cutting-edge pharmacists who have developed and implemented patient care services. This opportunity will help to hone the clinical skills and to prepare for a role as a pharmacy leader [12].

As the main force of hospital pharmacy discipline, clinical pharmacists should define their directions (e.g., tumor, cardiovascular, ophthalmology); their focus (e.g., immunotherapy, endocrine therapy, targeted therapy), skill directions (e.g., evidence-based medicine, pharmacoeconomics, quantitative pharmacology, bioinformatics, and clinical research) as experts.

\section{Continuing education opportunities}

Though pharmacist-education types vary around different countries or even regions, the mainstream is from student education 
to pharmacist licensing and academic continuing education in the areas they have trained for. The international entry levels focus on school education, for example, university training (basic studies and main studies) and practical training (community pharmacy/ hospital pharmacy/ industry) in Germany. In the United States, the Pharm. D. are eligible to enter the pharmacy field. In Poland, pharmacists must complete a 5.5-year Master of Pharmacy Program at medical university and obtain the right to practice from District Pharmaceutical Council. All Polish pharmacists have to maintain an adequate knowledge level by participating in various university- and industry-based courses and arrangements or by undergoing postgraduate specialization [13].

Continuing education is important for developing and updating pharmacists' knowledge, skills, and attitudes [14], especially for new pharmacists, inpatient/outpatient pharmacists, pharmacy technicians, and health care professionals. There are two professional education modes in China: Licensed Pharmacist and Hospital Pharmacist. For Licensed Pharmacists, education is in the form of centralized teaching or online teaching (also exams in some regions). For hospital pharmacists, education is in the form of a CME program (Continuing Education Management program), in which two types of scores (class I and class II) must be obtained by pharmacists each year [15].

The whole world has been experiencing the outbreak of COVID-19 (coronavirus disease-19) since the end of 2019 [16]. It also led to further growth in the number of articles published each year in international medical journals; in addition to doctors and nurses, hospital and clinical pharmacists also struggle to keep up to date [17]. A collaborative advanced pharmacy practice experience (APPE) education model is established within a healthcare institution during the COVID-19 pandemic. A health system can leverage institutional, network-wide, and academic partner resources to implement a collaborative APPE curriculum during challenging times such as those experienced during the COVID-19 pandemic [18]. There are also new modes for on-line/off-line education in China since 2020 .

\section{Working abroad}

There are opportunities for top pharmacists to work abroad, especially for clinical pharmacists: postgraduate education, overseas exchange program, professional training, overseas visit and study, overseas academic associations.

\section{Long-range vision}

Pharmacists apply their knowledge into clinical practice, infuse general drug usage into clinical diagnosis and treatment. At the same time, they apply basic skills onto patients, disseminate safe and effective drug policies and processes. Pharmacists are accountable for optimizing medication use (optimal, safe, and effective for all people all the time) to improve patient outcomes [19]. This concept requires the ability of pharmacists to discover and solve potential and practical clinical medication problems, to find new standpoints from directly-facing patients for clinical pharmacy and hospital pharmacy.

The most efficient pharmaceutic service in a hospital is that who will coordinate and integrate every pharmacy-group-function to form a cohesive organization with pharmacists, pharmacy technicians, and other student pharmacists in drug management, pharmacy care, medication policy, quality control, informatics, drug preparation, and drug dispensing. During the entire cancer medication process completed by interdisciplinary teams, cancer pharmacists will stand as the unique professionals with deep and comprehensive medication knowledge, and therefore will be the leaders on medication.

\section{References}

1. Santschi V. Impact of Pharmacist Care in the Management of Cardiovascular Disease Risk Factors. Archives of Internal Medicine 2011; 171(16): 1441

2. Ghaibi S, Ipema H, Gabay M. ASHP Guidelines on the Pharmacist's Role in Providing Drug Information. NA. 2015; 72(7): 573-577.

3. Chunyu Li, Tong Liu, Wei Chen, Min Liu, Guohui Li. Application of Pharmaceutical Management and Quality Control of Cancer Drugs in Teaching. Evaluation and analysis of drug-use in hospitals of China 2020; 20(5): 625-627.

4. Jincheng Yang. Current Situation and Management of Pharmacy Laboratory in Hospital. China Pharmaceuticals 2016; 25(10): $4-6$.

5. No-authors-listed. ASHP Guidelines on Clinical Drug Research. NA. 1998; 55(4): 369-375.

6. APhA. Featured Jobs: American Pharmacists Association; 2020 [Available from: https://jobs.pharmacist.com/.

7. APhA. The Board of Pharmacy Specialties 2020 [Available from: https://www.bpsweb.org/.

8. Hongxia Shi JZ, Yunhua He, Yue Li, Lin Yang. Discussion on the Teaching Mode of Standardized Training for Hospital Dispensing Pharmacists in Traditional Chinese Medicine Pharmacy. China Continuing Medical Education 2020; 12 (22): 41-44.

9. Shuang Ren, Jing Bian, Danwei Wu, Jiancun Zhen, Wei Zhang. Investigation on Optimization of Standardized Training Mode for Resident Pharmacists in Beijing. China Pharmacy. 2020; 31(6): $755-758$.

10. Jincheng Yang, Huiling Wang, Xiaofei Fei, Jun Yang. Thinking of Reform on Hospital Pharmacy Under the Background of New Healthcare Reform. China Pharmaceuticals 2019; 28(2): 93-95.

11. Rongjuan Cao QL, Xiangyun Meng. Application of Stratified Training Mode in Hospital Phannacist Training. Medical Information 2019; 32(3): 28-30. 
12. APhA. Post Graduate Opportunities 2020 [Available from: https:// www.pharmacist.com/post-graduate-opportunities.

13. Wikipedia. Pharmacist 2021 [Available from: https://encyclopedia.thefreedictionary.com/pharmacist.

14. Terajima T, Matsushita K, Yamada S, Suzuki H, Yano S, Makimura M, et al. Perspectives on Continuing Education Programs for Foundation-Level Drugstore Pharmacists in Japan. Pharmacy 2020; 8(4): 223

15. Qing Yang, Shuxiang Li, Huisheng Liu, Yongze Zhang. Research and enlightenment on mode of pharmacist's continuing professional development in Australia. Chinese Journal of Hospital Pharmacy 2020(13): 1491-1494.
16. Jincheng Yang, Zhe Chen, Bei Jia. Higher COVID-19 risk for patients with cancer. MedComm. 2020; 1(3): 418-419.

17. Fiore RD. The updating of the hospital pharmacist. Orient yourself in a sea of information and knowledge. Recenti Prog Med. 2021; 112(1): 22-24

18. Montepara CA, Schoen RR, Guarascio AJ, McConaha JL, Horn PJ. Health-system implementation of a collaborative core curriculum for advanced pharmacy experiential education during the COVID19 pandemic. NA. 2021.

19. No-authors-listed. ASHP long-range vision for the pharmacy workforce in hospitals and health systems. NA. 2020; 77(5): $386-400$. 